\title{
Article \\ Role of Nickel Content in One-Way and Two-Way Shape Recovery in Binary Ti-Ni Alloys
}

\author{
Elena P. Ryklina *, Kristina A. Polyakova and Sergey D. Prokoshkin
}

Citation: Ryklina, E.P.; Polyakova,

K.A.; Prokoshkin, S.D. Role of Nickel Content in One-Way and Two-Way Shape Recovery in Binary Ti-Ni Alloys. Metals 2021, 11, 119. https:// doi.org/10.3390/met11010119

Received: 23 December 2020 Accepted: 7 January 2021 Published: 9 January 2021

Publisher's Note: MDPI stays neutral with regard to jurisdictional clai$\mathrm{ms}$ in published maps and institutional affiliations.

Copyright: (C) 2021 by the authors. Licensee MDPI, Basel, Switzerland. This article is an open access article distributed under the terms and conditions of the Creative Commons Attribution (CC BY) license (https:// creativecommons.org/licenses/by/ $4.0 /)$.

\author{
Metal Forming Department, National University of Science and Technology MISIS, 119049 Moscow, Russia; \\ vachiyan@yandex.ru (K.A.P.); prokoshkin@tmo.misis.ru (S.D.P.) \\ * Correspondence: ryklina@tmo.misis.com
}

\begin{abstract}
The shape recovery characteristics of titanium nickelide with an Ni content of 50.0 at \% and 50.7 at \% were studied in a wide range of structures obtained as a result of cold drawing with an accumulated true strain of $\mathrm{e}=0.52$ and subsequent annealing in the 250 to $700{ }^{\circ} \mathrm{C}$ temperature range. Shape memory effect (SME) inducing was carried out by bending using a non-isothermal loading mode, which made it possible to reveal implementing elastic strain in the equiatomic alloy up to $12 \%$ and thereby increase the total shape recovery by a factor of 1.5 . The obtained results prove that the Ni content strongly affects the value and specific features of changes of the shape recovery characteristics with loading strain as well as grain/subgrain size. In equiatomic alloy, the total recovery strain manifests its maximum of $13.5-15 \%$ and the recovery strain of $9 \%$ at a loading strain range of 12 to $14 \%$. In Ni-rich alloy, the total recovery strain manifests its maximum of $20 \%$ and the recovery strain of $14 \%$ at a loading strain range of 15 to $21 \%$. The maximum two-way SME value correlates with the residual strain in both alloys and reaches its maximum of $3.0 \%$ in a material with a recrystallized structure. Varying the loading strain value under bending in the 11 to $21 \%$ range allows regulation of the temperature of shape recovery in Ni-rich alloy in the 45 to $80^{\circ} \mathrm{C}$ range.
\end{abstract}

Keywords: titanium nickelide; microstructure evolution; softening; martensitic transformations; shape recovery characteristics; comparative study

\section{Introduction}

Ti-Ni-based shape memory alloys (SMAs) of near-equiatomic compositions (with $\mathrm{Ni}$ content in the range of $0-50.9$ at \%) remain the most popular as functional materials with a unique set of functional properties. The scope of their application is extremely wide-from intelligent devices for space technologies [1,2] to medical implants [3-5]. In fundamental research and development of various kinds of devices, the attention of scholars and engineers is aimed at ensuring high shape recovery properties: superelasticity (pseudoelasticity), one-way shape memory effect (SME), two-way SME (TWSME), and shape recovery temperatures.

These properties are sensitive to structure, which determines the possibility of using various structural factors for their purposeful control [6-10]. Traditionally, for this purpose, a thermomechanical treatment is used. During post-deformation annealing (PDA), the recovery, polygonization, and recrystallization processes develop. In Ni-rich alloy, these structure changes are accompanied by aging in the 250 to $500{ }^{\circ} \mathrm{C}$ temperature range, i.e., precipitation of the $\mathrm{Ti}_{3} \mathrm{Ni}_{4}$ phase [11,12]. The intensity and completeness of aging in the given temperature range is determined by the temperature and exposure time [13-16]. Structure evolution under aging brings changes in the kinetics, sequence, and staging of martensitic transformations (MT) [17,18], which determine both shape recovery characteristics and the thermomechanical conditions for their implementation [18,19].

To induce SMEs, at least a single deformation is required. Various researchers use various loading modes-bending [20-23], tension [24,25], rolling [26], torsion [27-29], and compression $[30,31]$ — wherein the studied materials are usually limited by a single 
alloy of a certain chemical composition. It does not seem possible to compare the shape recovery characteristics obtained under different loading modes and strains as well as under different temperatures because the numerated conditions strongly affect shape recovery values [26,32-34]. To reveal the role of $\mathrm{Ni}$ content in Ti-Ni alloys, it is necessary to carry out the systematic comparative studies of at least two alloys-equiatomic and Ni-rich-in a wide range of structures using a similar approach.

The present work focuses on this objective and aims at revealing the effect of $\mathrm{Ni}$ content in binary Ti-Ni alloys on one-way and two-way SMEs as well as additional possibilities of their control according to specific task.

\section{Materials and Methods}

A Ti-50.0 at \% Ni alloy was obtained by "MATEK-SMA" (Russia) using vacuuminduction melting furnace (UPPF-3M, Elecktromechanika, Rzhev, Russia); a Ti-50.7 at $\% \mathrm{Ni}$ alloy was smelted using an induction vacuum skull melting furnace. Subsequent redistribution included pressing, rotary forging, hot helical rolling, and warm drawing to obtain a wire with a diameter of $0.58 \mathrm{~mm}$. The final homogenizing annealing was carried out at $700{ }^{\circ} \mathrm{C}(20 \mathrm{~min})$ with subsequent water quenching. A $0.45 \mathrm{~mm}$ diam. wire was obtained by the final cold drawing with a logarithmic area reduction (accumulated true strain) of e $=\ln \left(S_{O} / S_{1}\right)=0.52$ where $S_{O}$ and $S_{1}$ are the wire cross-section area before and after cold drawing The heat treatment regimes in the range of $250-700{ }^{\circ} \mathrm{C}$ were chosen using data from $[9,35,36]$ to obtain the full spectrum of structures under softening. Structural studies were carried out using a JEM-2100 transmission electron microscope (TEM, JEOL, Tokyo, Japan) operated at $200 \mathrm{kV}$. Foils were cut off the middle of the wire samples using a scanning ion microscope "Strata FIB 205" (FEI Company, Hillsboro, OR, USA) by local precision ion etching, with the accelerating voltage of a focused ion beam of $30 \mathrm{kV}$. Calorimetric studies of the martensitic transformations of a Ni-rich alloy were carried out using a "Perkin Elmer" calorimeter (Perkin Elmer LLC, Waltham, MA, USA) under a heating/cooling rate of $10{ }^{\circ} \mathrm{C} / \mathrm{min}$ in the range of -150 to $100^{\circ} \mathrm{C}$. The start and finish temperatures of martensitic transformations were determined using the ASTM F2004-05 (2010) standard [37]. The SME inducing was performed by bending using the loop-like wire samples (see Figure 1a) and the mode including the following steps: loading at a peak temperature $\mathrm{B} 2 \rightarrow \mathrm{R}$ transformation, then cooling to a temperature of zero for equiatomic alloy and $-196{ }^{\circ} \mathrm{C}$ for Ni-rich alloy, and unloading at the same temperature and heating. The corresponding peak temperatures for the equiatomic alloy were determined using the DSC plots presented in [9]. The samples were deformed using the cylindrical mandrels of different diameters equipped with a hook (Figure 1a) to fix the loop of the sample. The diameter of the arc formed by the sample at different stages of the experiment was measured using a template with a set of arcs of different diameters [19]. Figure 1a shows the loading procedure and Figure $1 \mathrm{~b}$ - a typical bending scheme with shape recovery characteristics. The loading strain $\left(\varepsilon_{t}\right)$ was varied in the range of $10-21 \%$. After unloading, the samples of the equiatomic alloy were gradually heated to 100 and $200{ }^{\circ} \mathrm{C}$; the samples of Ni-rich alloy were heated to $100^{\circ} \mathrm{C}$.

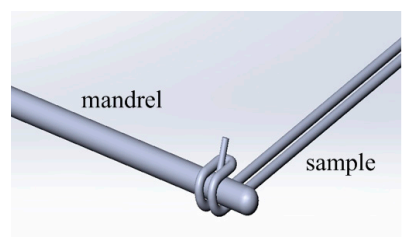

a

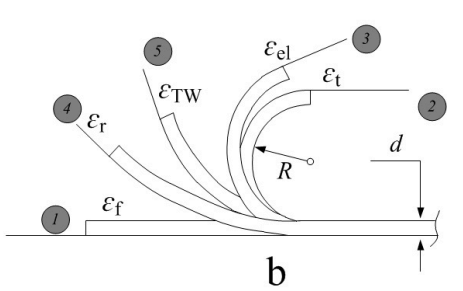

b

Figure 1. Shape memory effect (SME) inducing and measurements of shape recovery parameters: (a) Deformation of the sample on the mandrel; (b) schematic representation of shape recovery process after bending with the designation of the determined parameters ( $\mathrm{R}=\mathrm{D} / 2$, see Formula (1); 1-2 loading; 2-2 cooling under loading; $2-3$ elastic recovery strain; 3-4 shape recovery process under heating; 4-5 two-way SME (TWSME) under cooling; adapted from [19]). 
The loading strain $\varepsilon_{t}$ (see Figure $1 \mathrm{~b}$ ) was determined as

$$
\varepsilon_{t}=\frac{d}{D+d}
$$

where $d$-the wire diameter, $\mathrm{mm}$; $D$-diameter of the mandrel used to deform the sample, $\mathrm{mm}$ (Figure $1 \mathrm{~b}$ indicates the radius of the mandrel $(\mathrm{R})$ ).

Total recovery strain includes the recovery strain $\left(\varepsilon_{r}\right)$ and the elastic strain $\left(\varepsilon_{e l}\right)$ :

$$
\varepsilon_{r}^{t o t}=\varepsilon_{r}+\varepsilon_{e l} .
$$

The formulas for the shape recovery values and their interrelations are given in [19].

\section{Results}

Varying the time and temperature of annealing after cold deformation, a full spectrum of structures of titanium nickelide under softening was obtained. As a result of cold drawing with an accumulated strain of $\mathrm{e}=0.52$, a developed dislocation substructure of B2 austenite with partial amorphization is formed in both alloys (Figure 2a). The structure evolution and DSC plots for Ni-rich alloy are presented in Figures 2 and 3 respectively; similar studies of the equiatomic alloy were performed in [9].
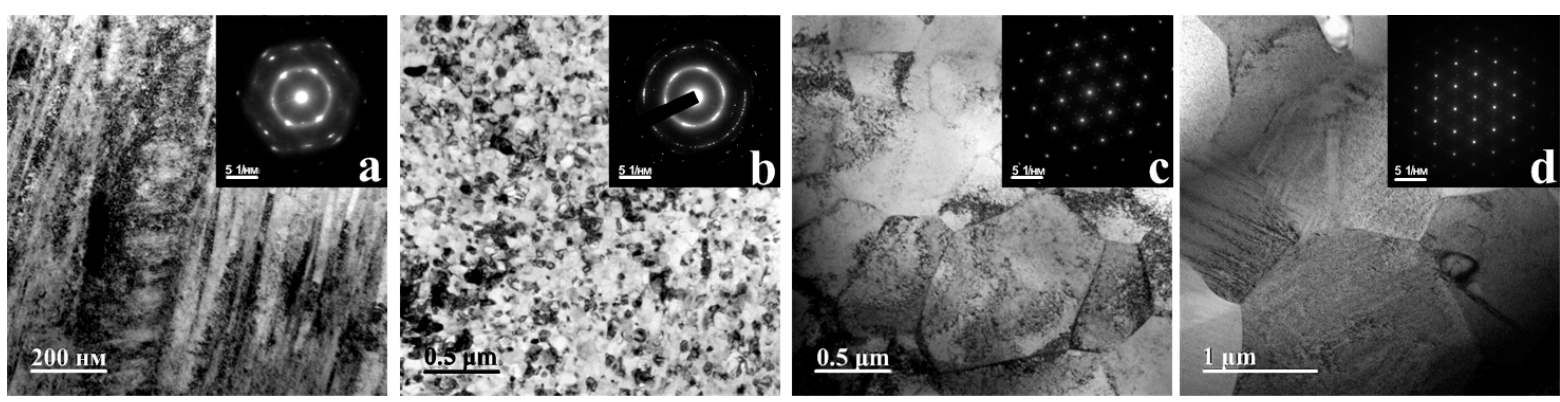

Figure 2. Microstructure (TEM) of Ti-50.7 at \% Ni alloy after drawing $(\mathrm{e}=0.52)$ and post-deformation annealing: (a) Asreceived after drawing; (b) $500{ }^{\circ} \mathrm{C}, 0.5 \mathrm{~h}$; (c) $600^{\circ} \mathrm{C}, 0.5 \mathrm{~h}$; (d) $650{ }^{\circ} \mathrm{C}, 0.5 \mathrm{~h}$.

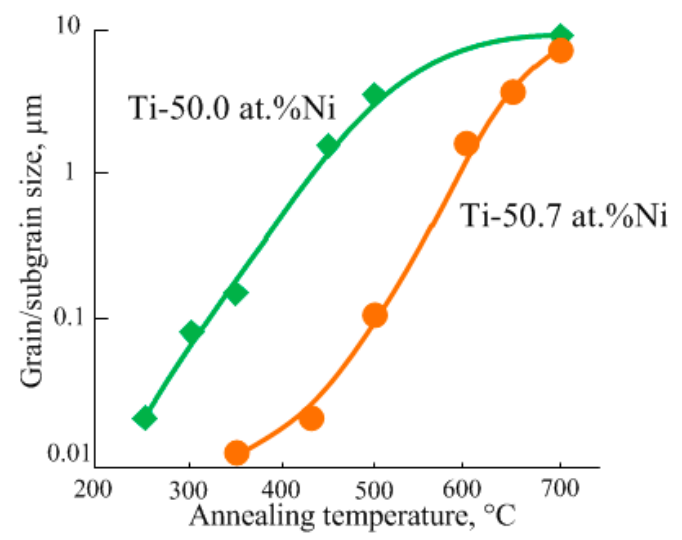

Figure 3. Grain/subgrain growth as a result of post-deformation annealing (the curve for equiatomic alloy was plotted using the data of [9]).

PDA at $350{ }^{\circ} \mathrm{C}$ is accompanied by recovery and initial polygonization. As a result of aging at $430{ }^{\circ} \mathrm{C}$, a mixed nanostructure of $\mathrm{B} 2$ austenite is observed; it consists of subgrains (formed in the areas with the well-developed dislocation substructure) and crystallized grains (formed in the amorphous areas); the average size of structure elements does not exceed $20 \mathrm{~nm}$. After aging at $500{ }^{\circ} \mathrm{C}$, the suppressing part of the volume is occupied by the recrystallized grains; the average size of microstructure elements increases to $80-120 \mathrm{~nm}$ 
(Figure $2 \mathrm{~b}$ ). After aging in the range of $350-500{ }^{\circ} \mathrm{C}$, the $\mathrm{Ti}_{3} \mathrm{Ni}_{4}$ precipitates cannot be traced visually but can be interpreted using selected area electron diffraction (SAED) $[35,38]$ and X-ray analysis [39]. Annealing at $600{ }^{\circ} \mathrm{C}$ leads to the completion of recrystallization, the grain size is 1.3-1.8 $\mu \mathrm{m}$ after exposure for $0.5 \mathrm{~h}$ and $3-4 \mu \mathrm{m}$ after exposure for $1 \mathrm{~h}$ (Figure 2d). An increase in the annealing temperature up to $700{ }^{\circ} \mathrm{C}(0.5 \mathrm{~h})$ is accompanied by an increase in the grain size to 7-9 microns [18].

The similar structure evolution was found in equiatomic alloy [9] with transition from one structure type to another at $100-150{ }^{\circ} \mathrm{C}$ lower temperatures. To compare the grain/subgrain size growth versus temperature grain/subgrain, the corresponding plots are given in Figure 3.

The DSC results shown in Figure 4 permit tracing the evolution of martensitic transformations in the development of softening.
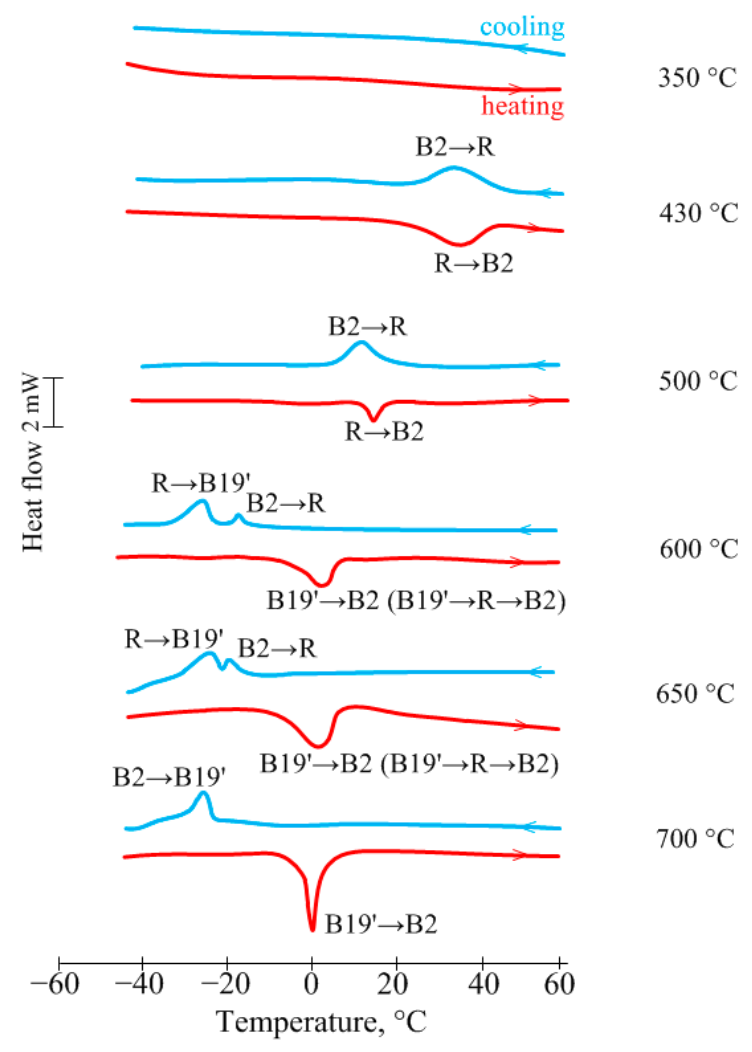

Figure 4. DSC curves of the Ti-50.7 at \% Ni alloy after various post-deformation annealings (only the temperature range is shown where martensitic transformations were recorded).

After annealing at $350{ }^{\circ} \mathrm{C}$, at the initial stage of softening, all martensitic transformations are suppressed. Aging at $430^{\circ} \mathrm{C}$ brings the appearance of a direct $\mathrm{B} 2 \rightarrow \mathrm{R}$ transformation at a temperature of $32{ }^{\circ} \mathrm{C}$ and a reverse $\mathrm{R} \rightarrow \mathrm{B} 2$ transformation at a temperature of $34{ }^{\circ} \mathrm{C}$. The growth of microstructure elements up to $80-120 \mathrm{~nm}$ (annealing at $500{ }^{\circ} \mathrm{C}$ ) shifts a temperature of $\mathrm{B} 2 \rightarrow \mathrm{R}$ transformation down to $10^{\circ} \mathrm{C}$. The formation of $\mathrm{B} 19^{\prime}$ martensite remains suppressed down to minus $100^{\circ} \mathrm{C}$ and becomes possible only upon completion of the recrystallization processes at $600{ }^{\circ} \mathrm{C}$ for $0.5 \mathrm{~h}$, when the average grain size reaches $1.3-1.8 \mu \mathrm{m}$. In this case, the peak of $\mathrm{B} 2 \rightarrow \mathrm{R}$ transformation shifts to minus $18^{\circ} \mathrm{C}$. An increase in the annealing time to $1 \mathrm{~h}$ at the same temperature of $600{ }^{\circ} \mathrm{C}$ (the average grain size is 3-4 $\mu \mathrm{m}$ ) brings peaks convergence and after PDA at $700{ }^{\circ} \mathrm{C}$ (average grain size $9-11 \mu \mathrm{m}$ ) transition to a one-stage transformation $\mathrm{B} 2 \rightarrow \mathrm{B} 19^{\prime}$. The reverse martensitic transformation remains one stage in all cases: it corresponds to $\mathrm{R} \rightarrow \mathrm{B} 2$ in the range of $430-500{ }^{\circ} \mathrm{C}$ and $\mathrm{B} 2 \rightarrow(\mathrm{R}) \rightarrow \mathrm{B} 19^{\prime}$ in the range of $600-700^{\circ} \mathrm{C}$.

SME inducing (loading) temperatures for each structural state were determined from the position of the B2 $\rightarrow$ R peak; they are presented in Table 1. Since all martensitic trans- 
formations are suppressed after annealing at $350{ }^{\circ} \mathrm{C}$, it is not possible to determine the SME inducing (i.e., loading) temperature. Therefore, taking into account the peak displacement trend toward low temperatures during the development of softening processes (see Figure 4), a deformation temperature of $50{ }^{\circ} \mathrm{C}$ was chosen.

Table 1. Loading temperatures for each structure state (correspond to the peak of the $B 2 \rightarrow R$ transformation).

\begin{tabular}{|c|c|c|c|c|c|c|}
\hline \multicolumn{7}{|c|}{ Ti-50.0 at \% Ni, Determined from [39] } \\
\hline PDA regimes & $250^{\circ} \mathrm{C}, 1 \mathrm{~h}$ & $300^{\circ} \mathrm{C}, 1 \mathrm{~h}$ & $350^{\circ} \mathrm{C}, 1 \mathrm{~h}$ & $450{ }^{\circ} \mathrm{C}, 0.5 \mathrm{~h}$ & $500^{\circ} \mathrm{C}, 1 \mathrm{~h}$ & $700{ }^{\circ} \mathrm{C}, 0.5 \mathrm{~h}$ \\
\hline $\begin{array}{c}\text { Position of } \\
\mathrm{B} 2 \rightarrow \mathrm{R} \text { peak, }{ }^{\circ} \mathrm{C}\end{array}$ & 50 & 45 & 45 & 45 & 42 & $40 *$ \\
\hline \multicolumn{7}{|c|}{ Ti-50.7 at $\% \mathrm{Ni}$} \\
\hline PDA regimes & $350{ }^{\circ} \mathrm{C}, 0.5 \mathrm{~h}$ & $430{ }^{\circ} \mathrm{C}, 0.5 \mathrm{~h}$ & $500{ }^{\circ} \mathrm{C}, 0.5 \mathrm{~h}$ & $600^{\circ} \mathrm{C}, 0.5 \mathrm{~h}$ & $650^{\circ} \mathrm{C}, 0.5 \mathrm{~h}$ & $700{ }^{\circ} \mathrm{C}, 0.5 \mathrm{~h}$ \\
\hline $\begin{array}{c}\text { Position of } \\
\mathrm{B} 2 \rightarrow \mathrm{R} \text { peak, }{ }^{\circ} \mathrm{C}\end{array}$ & 50 & 32 & 10 & -18 & -18 & $-21^{*}$ \\
\hline
\end{tabular}

*-In the absence of $\mathrm{B} 2 \rightarrow \mathrm{R}$ transformation, the loading temperature corresponds to the onset of the martensitic transformation $\mathrm{B} 2 \rightarrow(\mathrm{R}) \rightarrow{\mathrm{B} 19^{\prime}}^{\prime}$

Figure 5 presents the selected results of the shape recovery characteristics of both alloys with a mixed nanostructure (see Figure $5 \mathrm{a}, \mathrm{c}$ ) and a recrystallized structure of B2austenite (see Figure $5 \mathrm{c}, \mathrm{d}$ ) vs. loading strain. The similar studies were carried out after annealing in all temperature ranges. Although the corresponding plots are omitted in Figure 5, the obtained data are presented in Figures 6 and 7.
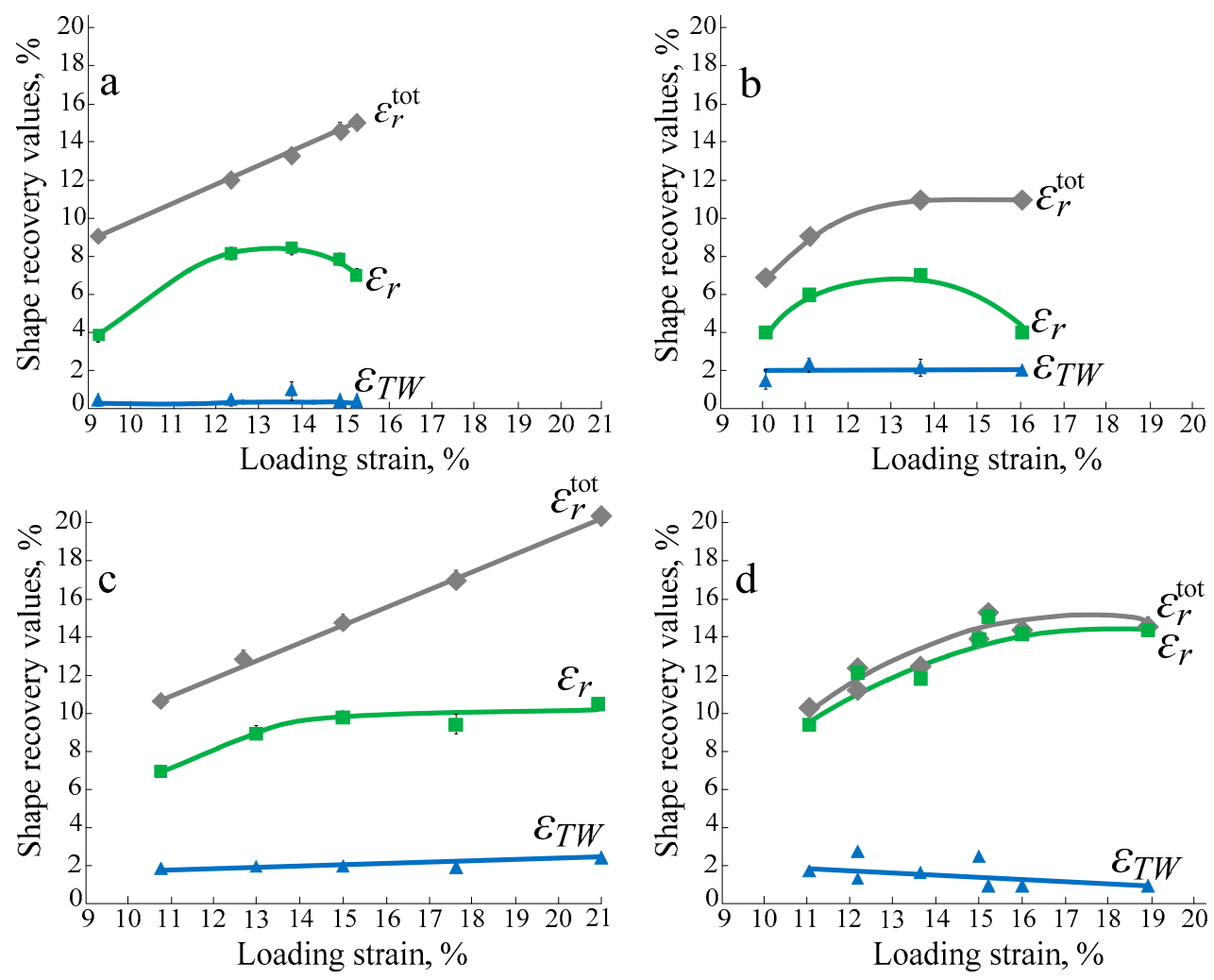

Figure 5. Shape recovery parameters vs. loading strain plots of Ti-50.0 at \% Ni (a,b) and Ti-50.7 at \% Ni (c,d) alloys with a mixed nanostructure $(\mathbf{a}, \mathbf{c})$ and recrystallized structure (b,d) after post-deformation annealings: (a) $350{ }^{\circ} \mathrm{C}, 1 \mathrm{~h} ;(\mathbf{b}) 500{ }^{\circ} \mathrm{C}$; $1 \mathrm{~h}$; (c) $500{ }^{\circ} \mathrm{C}, 0.5 \mathrm{~h}$; (d) $600{ }^{\circ} \mathrm{C}, 0.5 \mathrm{~h}$. 

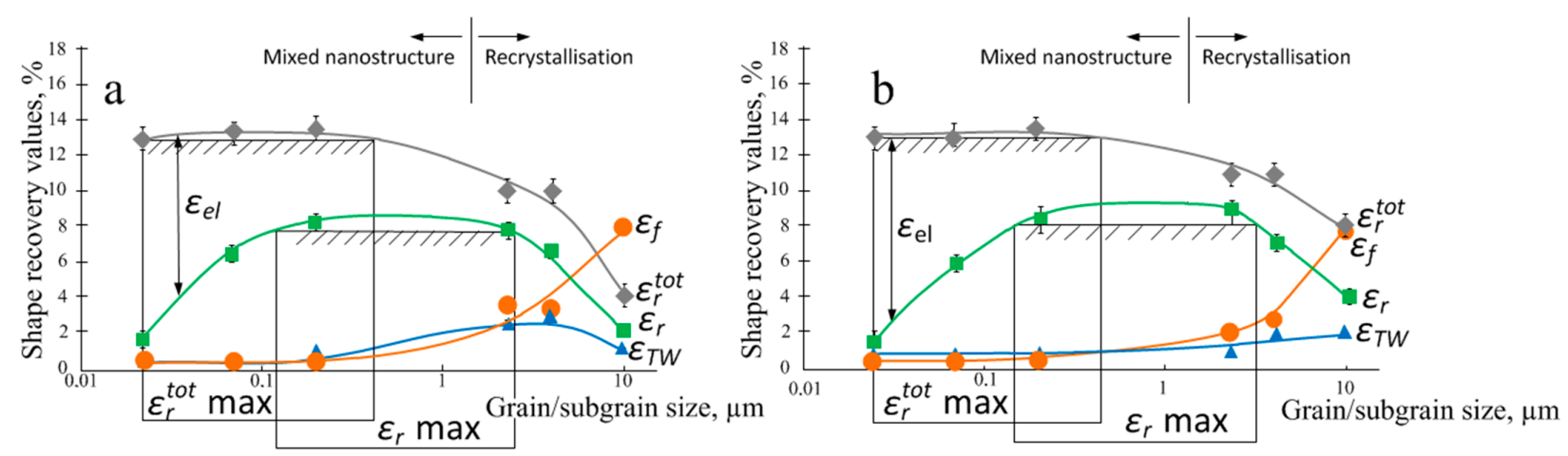

Figure 6. Shape recovery parameters vs. grain/subgrain size plots of equiatomic alloy in the $\varepsilon_{t}=12-14 \%$ range after heating up to (a) $100{ }^{\circ} \mathrm{C}$ and (b) $200{ }^{\circ} \mathrm{C}$. The range of grain/subgrain size corresponding to the maximum values of $\varepsilon_{r}$ and $\varepsilon_{r}^{t o t}$ is marked by shading.

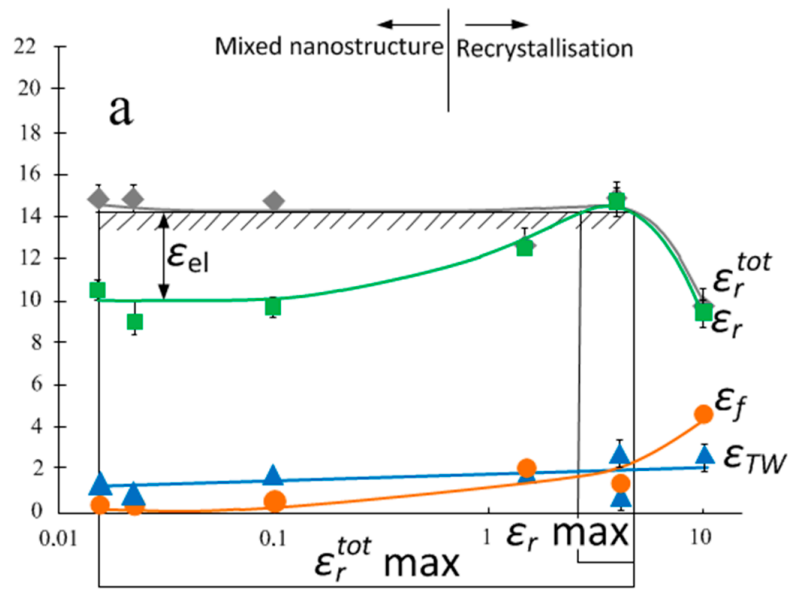

Grain/subgrain size, $\mu \mathrm{m}$

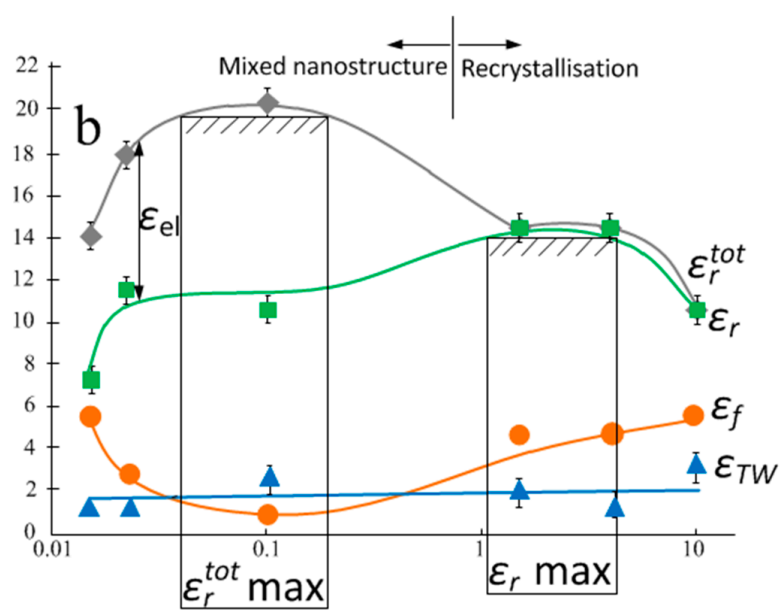

Grain/subgrain size, $\mu \mathrm{m}$

Figure 7. Shape recovery parameters vs. grain/subgrain size plots of Ni-rich alloy in the ranges of loading strain: (a) 15-16\%; (b) $19-20 \%$. The range of grain/subgrain size corresponding to the maximum values of $\varepsilon_{r}$ and $\varepsilon_{r}^{\text {tot }}$ is marked by shading.

In all cases, an equiatomic alloy manifests an extreme character in the recovery strain evolution with a maximum in a range of loading strain of $12-14 \%$ (see Figure $5 \mathrm{a}, \mathrm{b}$ ). The recovery strain value manifests its maximum of $9 \%$ in a nanostructured material (see Figure 5a) and decreases to $6 \%$ in a recrystallized one (see Figure $5 b$ ).

In Ni-rich alloy, the recovery strain manifests a parabolic dependence with a maximum value of $14 \%$ in a range of loading strain of $10-21 \%$. The $\varepsilon_{r}$ value does not exceed $10 \%$ in a nanostructured alloy (see Figure $5 \mathrm{c})$ and reaches $14 \%$ in a fine-grained $(\approx 3 \mu \mathrm{m})$ recrystallized alloy (see Figure 5d).

The total recovery strain $\varepsilon_{r}^{\text {tot }}$ includes as well the elastic strain, changes in direct ratio in both alloys with a mixed nanostructure, and parabolic dependence in the case of a fine-grained recrystallized structure. It reaches $15 \%$ and $20 \%$ respectively in an equiatomic alloy and an Ni-rich one. The TWSME value in the presented plots does not exceed $2 \%$.

Note that the shape recovery value as well as the position of its maximum under heating differs in the studied alloys: in the equiatomic alloy, it corresponds to the range of $\varepsilon_{t}=12-14 \%$ (see Figure 5a,b), and $\varepsilon_{t}=15-21 \%$ for the Ni-rich alloy (see Figure 5c,d).

The loading strain strongly affects the shape recovery temperatures of Ni-rich alloy: the increase from 45 to $80^{\circ} \mathrm{C}$ correlates with the increase of loading strain in the range of $11-21 \%$.

Figure 6 presents the diagrams of shape recovery values vs. grain/subgrain size of an equiatomic alloy after SME inducing, subsequent unloading, and heating up to $100{ }^{\circ} \mathrm{C}$ (see Figure 6a) and $200{ }^{\circ} \mathrm{C}$ (see Figure 6b). The diagrams were plotted using shape recovery 
values obtained in the range of loading strain of $12-14 \%$. The value of the elastic strain $\varepsilon_{e l}$ is marked by an arrow.

After unloading and heating up to $100{ }^{\circ} \mathrm{C}$, the recovery strain maximum $\varepsilon_{r}=8 \pm 0.5 \%$ is realized in the range of grain/subgrain size $0.07-2.3 \mu \mathrm{m}$ (see Figure 6a), and the total recovery strain manifests its maximum $\varepsilon_{r}^{t o t}=13.5 \pm 0.7 \%$ in the range of $0.03-0.6 \mu \mathrm{m}$. This range is characterized by the maximum contribution of the elastic strain.

The grain/subgrain refinement lower than $0.03 \mu \mathrm{m}$ as well as the development of recrystallization brings degradation of the recovery strain $\varepsilon_{r}$; the total recovery strain $\varepsilon_{r}^{\text {tot }}$ decreases only with the recrystallized grain growth.

The residual strain $\varepsilon_{f}$ remains minimal in the range of ultra-fine-grained substructure and gradually increases with the growth of the grain/subgrain size. The TWSME value correlates with the residual strain in the range of $0.2-6.0 \mu \mathrm{m}$ of the structure elements, reaches its maximum $2.5 \%$ in the range of $1.5-2.5 \mu \mathrm{m}$, and then decreases.

After unloading and heating up to $200{ }^{\circ} \mathrm{C}$, the recovery strain increases up to $9 \pm 0.5 \%$. The value of $\varepsilon_{r}^{\text {tot }}$ increases in the material with the recrystallized structure by $2-4 \%$ (see Figure $5 b$ ). The TWSME value decreases, and the residual strain does not change.

For similar diagrams of Ni-rich alloy, two ranges of loading strain were chosen: $15-16 \%$ and $19-20 \%$. The recovery strain manifests an extreme character of evolution with a maximum of $15 \pm 0.5 \%$ in the narrow range of the $2-5 \mu \mathrm{m}$ of the fine-grained recrystallized structure. At that, the total recovery strain $\varepsilon_{r}^{t o t}$ manifests a stable plateau at $\varepsilon_{r}=13.5 \pm 0.5 \%$ in a wide "structure range" of $0.07-5.0 \mu \mathrm{m}$ (see Figure $7 \mathrm{a}$ ); the grain growth up to $9-11 \mu \mathrm{m}$ brings their expressed degradation.

The residual strain $\varepsilon_{f}$ does not exceed $0.2 \%$ up to a grain/subgrain size of $0.1 \mu \mathrm{m}$ and approaches $5 \%$ in the range of existence of the recrystallized structure with the grain size of $7-9 \mu \mathrm{m}$. The TWSME value gradually increases from $1 \%$ in the material with the finest mixed nanostructure to $2.6 \%$ with the development of recrystallization.

The increase of the loading strain up to $19-20 \%$ (Figure $7 \mathrm{~b}$ ) brings the increase of the total recovery strain $\varepsilon_{r}^{\text {tot }}$ up to $20 \%$ (which almost coincides with the loading strain) in the narrow range of $0.05-0.2 \mathrm{~nm}$. The $\varepsilon_{r}$ value remains the same, and its "structure range" somewhat expands to 1-6 $\mu \mathrm{m}$. The TWSME maximum of $3 \%$ correlates with that of the residual strain of $5 \%$.

\section{Discussion}

The described regularities prove that the Ni content in binary titanium nickelide strongly affects the value and specific features of the shape recovery characteristics. The range of their maximum realization is $\varepsilon_{t}=12-14 \%$ for the equiatomic alloy (see Figure $5 \mathrm{a}, \mathrm{b}$ ) and $\varepsilon_{t}=15-21 \%$ for Ni-rich alloy (see Figure $5 c$,d). The maximum recovery strain $\varepsilon_{r}$ in equiatomic alloy does not exceed 9\%; in Ni-rich alloy, it reaches 14\%. The maximum total recovery strain $\varepsilon_{r}$ reaches $15 \%$, in equiatomic alloy and $20 \%$ in Ni-rich one (see Figures $5-7$ ). A comparative analysis makes it possible to explain the difference between the observed regularities in the functional behavior of alloys with different Ni content.

Under non-isothermal annealing in an equiatomic alloy, only softening processes occur; in Ni-rich alloys during annealing, softening and aging (with precipitation of the $\mathrm{Ti}_{3} \mathrm{Ni}_{4}$ phase) proceed simultaneously; i.e., there is an overlap of "structural" and "morphological" factors (meaning the structure of the matrix and the morphology of precipitates, respectively). Note that the processes of softening develop with the temperature growth, although the aging process develops in the range of $250-500{ }^{\circ} \mathrm{C}[11,12]$ with a maximum of $420-440{ }^{\circ} \mathrm{C}$ in its intensity and depth $[15,40]$. Figure 3 shows that all the stages of softening in the temperature range of $350-500{ }^{\circ} \mathrm{C}$ in Ni-rich alloy begin at higher temperatures if compared to an equiatomic alloy with the difference range of $100-150^{\circ} \mathrm{C}$. This phenomenon of "delay" is associated with the decorating effect of the $\mathrm{Ti}_{3} \mathrm{Ni}_{4}$ precipitates along grain boundaries in the Ni-rich alloy during annealing in the temperature range of $350-500{ }^{\circ} \mathrm{C}$, which results in an obstacle to the migration of dislocations, dislocation sub-boundaries, and grain boundaries [9]. On the other hand, the precipitates create an orienting effect, i.e., 
additional powerful fields of internal stresses, which "work" to improve the shape recovery behavior associated with the availability of martensitic transformations; this contribution is most pronounced in the temperature range of $350-500{ }^{\circ} \mathrm{C}$, when the aging processes are most intense.

In Ni-rich alloy, the initial stage of softening (PDA at $350{ }^{\circ} \mathrm{C}$ ) is characterized by the suppression of all phase transformation (see Figure 4) that is caused by the preservation of high defectiveness of the structure. The development of poligonization and grain/subgrain growth after PDA at $430{ }^{\circ} \mathrm{C}$ causes in the appearance of $\mathrm{B} 2 \rightarrow \mathrm{R}$ transformation; its highest temperature is associated with the most intense aging processes $[18,35]$.

A further decline of $\mathrm{B} 2 \rightarrow \mathrm{R}$ transformation is associated with the stabilization of B2 austenite due to a decrease in the structure defectiveness and the development of recrystallization processes. This tendency persists with a further increase in the annealing temperatures and the development of recrystallization.

The suppression of the martensitic transformation $\mathrm{R} \rightarrow \mathrm{B} 19^{\prime}$ in the annealing temperature range of $430-500{ }^{\circ} \mathrm{C}$ is associated with the formation of a nanostructure $[9,35]$. These regularities fit into the known data of the evolution of martensitic transformations inherent in aging Ti-Ni-based alloys [9,40,41]. Comparison with the evolution of the martensitic transformations in the equiatomic alloy [9] confirms the "delay" phenomenon in structural evolution mentioned above.

The specific features of structure formation and martensitic transformations described above reflect the shape recovery behavior and the values of the studied parameters. To analyze the nature of this effect, the following considerations should be taken into account. The shape recovery value is determined by the difference between the dislocation (conventional) and the transformation yield stress $\Delta \sigma$ [42]. The higher this difference, the later the irreversible plastic deformation starts under loading. Aging results in an increase of the dislocation yield stress as well as $\Delta \sigma$, which is a value that confidently correlates with the shape recovery values in Ni-rich alloy [19].

It was found in [41] that $\Delta \sigma$ is lower in the equiatomic alloy vs. the Ni-rich one. Therefore, when using the same loading strain, irreversible plastic deformation in an equiatomic alloy starts at lower deformations than in a Ni-rich one. The above arguments confirm that the observed difference in the shape recovery behavior of equiatomic and Ni-rich alloy is logical and regular.

Despite the fact that the high defectiveness of the structure after annealing in the range of $250-350{ }^{\circ} \mathrm{C}$ (for equiatomic alloy) and $350-500{ }^{\circ} \mathrm{C}$ (for Ni-rich alloy) causes the suppression of the $\mathrm{R} \rightarrow \mathrm{B}^{\prime} 9^{\prime}$ transformation (see Figure 4 ), the relatively high values of the recovery strain of both alloys indicate that the realization of martensitic transformations becomes possible under load (see Figures 5-7).

In all works devoted to the shape recovery study of an equiatomic alloy from [8] to [43], it was shown that the maximum recovery strain does not exceed $8 \%$, and the elastic recovery strain is near zero. The use of a non-isothermal loading mode in the present study makes it possible to realize relatively high values of the elastic strain (up to 5-8\%) and thereby to increase the total recovery strain up to $13-15 \%$. The shape recovery nature when using the mentioned mode is explained in [20]: it is caused by stabilization of the stressinduced martensite under cooling in a loaded condition. The contribution of the elastic strain in shape recovery is maximal in a fine grained/subgrained material and degrades due to recrystallization. Note that the $\varepsilon_{r}^{\text {tot }}$ value exceeds the crystallographic resource of the lattice deformation of an equiatomic alloy by 1.5 times. The grain/subgrain refinement lower than $0.07 \mu \mathrm{m}$ causes the degradation of the recovery stress due to the suppression of martensitic transformation $\mathrm{R} \rightarrow \mathrm{B} 19^{\prime}$; the grain growth brings the degradation of the recovery stress due to decrease of the $\Delta \sigma$ value.

The described correlation between the TWSME value $\left(\varepsilon_{T W}\right)$ and the residual strain $\left(\varepsilon_{f}\right)$ in the equiatomic alloy after subsequent heating up to $100{ }^{\circ} \mathrm{C}$ and then $200{ }^{\circ} \mathrm{C}$ testifies to the role of the residual stress in realization of the TWSME value. To achieve the maximum 
value of the TWSME value, heating to lower temperatures (up to $100{ }^{\circ} \mathrm{C}$ ) is preferable, at which point the process of relaxation of residual stresses has not yet developed.

The obtained results can be used as an additional approach for the precise regulation of the shape recovery properties in Ti-Ni-based alloys.

As a result of the systematic comparative study of structure evolution, martensitic transformations, and shape recovery characteristics of titanium nickelide with the nickel content of 50.0 at $\%$ and 50.7 at \%, the following conclusions are formulated.

\section{Conclusions}

1. The Ni content in a binary titanium nickelide strongly affects the value and specific features of the shape recovery characteristics:

- The equiatomic alloy manifests its maximum values at 12 to $14 \%$ of the loading strain range, while the Ni-rich alloy manifests its maximum values in the 15 to $21 \%$ range;

- In equiatomic alloy, the total recovery strain manifests its maximum of 13.5 to $15 \%$ in the range of grain/subgrain sizes of $0.03-0.6 \mu \mathrm{m}$ and the recovery strain manifests its maximum of $9 \%$ in the grain/subgrain size range of 0.2 to $3 \mu \mathrm{m}$;

- In Ni-rich alloy, the total recovery strain manifests its maximum of $20 \%$ in the range of grain/subgrain sizes of 0.05 to $0.2 \mu \mathrm{m}$, and the recovery strain manifests its maximum of $14 \%$ in the range of grain/subgrain sizes of 0.2 to $3 \mu \mathrm{m}$;

2. The use of the non-isothermal SME inducing mode made it possible for the first time to reveal the possibility of implementing elastic strain in the equiatomic alloy up to $12 \%$ and thereby increase the total shape recovery by 1.5 times. The maximum contribution of the elastic strain in shape recovery in both alloys is realized in a material with the ultra-fine-grained structure with the grain/subgrain size up to $0.5 \mu \mathrm{m}$.

3. The maximum TWSME value correlates with the residual strain in both alloys and reaches its maximum of $3.0 \%$ in a material with a recrystallized structure.

4. Varying the loading strain value by bending in the 11 to $21 \%$ of strain range allows regulation of the temperature of shape recovery in Ni-rich alloy in the 45 to $80{ }^{\circ} \mathrm{C}$ range.

5. The revealed regularities can be used as additional tools for the control of shape recovery values in titanium nickelide according to the objectives of its various applications.

Author Contributions: Conceptualization, E.P.R.; methodology, E.P.R.; software, K.A.P.; validation, E.P.R., K.A.P., and S.D.P.; formal analysis, E.P.R. and S.D.P.; investigation, E.P.R. and K.A.P.; resources, E.P.R. and S.D.P.; data curation, E.P.R. and K.A.P.; writing-original draft preparation, E.P.R.; writingreview and editing, E.P.R. and S.D.P.; visualization, K.A.P.; supervision, K.A.P.; project administration, K.A.P. All authors have read and agreed to the published version of the manuscript.

Funding: The work was funded out with the financial support of the Russian Science Foundation (Project No. 19-79-00365) in part of TEM and functional characterization of the Ti-50.7 at \% Ni and Ministry of Science and Higher Education of the Russian Federation in the framework of the State Task (project code 0718-2020-0030) in part of functional characterization of the Ti-50.0 at \% Ni.

Institutional Review Board Statement: Not applicable.

Informed Consent Statement: Not applicable.

Data Availability Statement: Not applicable.

Acknowledgments: The DSC study was performed by K. Inaekyan using the facilities of Ecole de Technologie Superieure, Montreal, QC, Canada.

Conflicts of Interest: The authors declare no conflict of interest. 


\section{References}

1. Razov, A.; Cherniavsky, A. Application of SMAs in modern spacecraft and devices. J. Phys. IV 2003, 112, 1173-1176.

2. Hartl, D.J.; Lagoudas, D.C. Aerospace applications of shape memory alloys. Proc. Inst. Mech. Eng. Part G J. Aerosp. Eng. 2007, 221, 535-552. [CrossRef]

3. Jani, J.M.; Leary, M.; Subic, A.; Gibson, M.A. A review of shape memory alloy research, applications and opportunities. Mater. Des. 2014, 56, 1078-1113. [CrossRef]

4. Morgan, N. Medical shape memory alloy applications-The market and its products. Mater. Sci. Eng. A 2004, 378, 16-23. [CrossRef]

5. Sabahi, N.; Chen, W.; Wang, C.-H.; Kruzic, J.J.; Li, X. A Review on Additive Manufacturing of Shape-Memory Materials for Biomedical Applications. JOM 2020, 72, 1229-1253. [CrossRef]

6. Miyazaki, S. Engineering Aspects of Shape Memory Alloys; Duerig, T.W., Ed.; Butterworth-Heinemann: Oxford, UK, $1990 ;$ p. 394.

7. Otsuka, K.; Wayman, C.M. (Eds.) Shape Memory Materials; Cambridge University Press: Cambridge, UK, 1998 ; p. 284.

8. Funakubo, H. (Ed.) Shape Memory Alloys; Gordon and Breach Science Publishers: New York, NY, USA, 1987 ; p. 275.

9. Inaekyan, K.E. Investigation of the Relationship between the Structure and Functional Properties of Thermomechanically Treated Shape Memory Ti-Ni-Based Alloys. Ph.D. Thesis, Moscow State Institute of Steel and Alloys, Moscow, Russia, 2006 ; p. 149. (In Russian).

10. Treppmann, D.; Hornbogen, E.; Wurzel, D. The Effect of Combined Recrystallization and Precipitation Processes on the Functional and Structural Properties in NiTi Alloys. J. Phys. Colloq. 1995, 5, 569-574. [CrossRef]

11. Nishida, M.; Wayman, C.; Honma, T. Electron microscopy studies of the Ti11Ni14 phase in an aged Ti-52.0 at \% Ni shape memory alloy. Scr. Metall. 1985, 19, 983-987. [CrossRef]

12. Tadaki, T.; Nakata, Y.; Shimizu, K.; Otsuka, K. Crystal Structure, Composition and Morphology of a Precipitate in an Aged Ti-51 at\% Ni Shape Memory Alloy. Trans. Jpn. Inst. Metals 1986, 27, 731-740. [CrossRef]

13. Khalil-Allafi, J.; Dlouhy, A.; Eggeler, G. Ni4Ti3-precipitation during aging of NiTi shape memory alloys and its influence on martensitic phase transformations. Acta Mater. 2002, 50, 4255-4274. [CrossRef]

14. Allafi, J.K.; Eggeler, G.; Dlouhy, A.; Schmahl, W.W.; Somsen, C. On the influence of heterogeneous precipitation on martensitic transformations in a Ni-rich NiTi shape memory alloy. Mater. Sci. Eng. A 2004, 378, 148-151. [CrossRef]

15. Ryklina, E.P.; Prokoshkin, S.D.; Chernavina, A.A.; Perevoshchikova, N.N. Investigation on the influence of thermomechanical conditions of induction and structure on the shape memory effects in Ti-Ni alloy. Inorg. Mater. Appl. Res. 2010, 1, 188-194. [CrossRef]

16. Ryklina, E.P.; Korotitskiy, A.; Khmelevskaya, I.; Prokoshkin, S.; Polyakova, K.; Kolobova, A.; Soutorine, M.; Chernov, A. Control of phase transformations and microstructure for optimum realization of one-way and two-way shape memory effects in removable surgical clips. Mater. Des. 2017, 136, 174-184. [CrossRef]

17. Ravari, B.K.; Farjami, S.; Nishida, M. Effects of Ni concentration and aging conditions on multistage martensitic transformation in aged Ni-rich Ti-Ni alloys. Acta Mater. 2014, 69, 17-29. [CrossRef]

18. Ryklina, E.P.; Polyakova, K.; Tabachkova, N.Y.; Resnina, N.; Prokoshkin, S. Effect of B2 austenite grain size and aging time on microstructure and transformation behavior of thermomechanically treated titanium nickelide. J. Alloy. Compd. 2018, 764, 626-638. [CrossRef]

19. Polyakova, K.; Ryklina, E.P.; Prokoshkin, S.D. Effect of Grain Size and Ageing-Induced Microstructure on Functional Characteristics of a Ti-50.7 at \% Ni Alloy. Shape Mem. Superelasticity 2020, 6, 139-147. [CrossRef]

20. Ryklina, E.P.; Polyakova, K.; Prokoshkin, S. Comparative Study of Shape Memory Effects in Ni-Rich Ti-Ni Alloy After Training in Various Phase States. Shape Mem. Superelasticity 2020, 6, 157-169. [CrossRef]

21. Komarov, V.; Khmelevskaya, I.; Karelin, R.; Prokoshkin, S.; Zaripova, M.; Isaenkova, M.; Korpala, G.; Kawalla, R. Effect of biaxial cyclic severe deformation on structure and properties of Ti-Ni alloys. J. Alloy. Compd. 2019, 797, 842-848. [CrossRef]

22. Belyaev, S.P.; Resnina, N.; Pilyugin, V.; Glazova, D.; Zeldovich, V.; Frolova, N. Shape memory effects in Ti-50.2 at\% Ni alloy with different grain size. Mater. Sci. Eng. A 2017, 706, 64-70. [CrossRef]

23. Kalashnikov, V.S.; Andreev, V.A.; Koledov, V.V.; Gunderov, D.V.; Petrov, A.V.; Shavrov, V.G.; Kuchin, D.V.; Gizatullin, R.M. Functional Characteristics and Phase Transformations in Bar Semiproducts from Shape Memory NiTi Alloys. Metal Sci. Heat Treat. 2019, 61, 504-510. [CrossRef]

24. Kim, J.; Miyazaki, S. Effect of nano-scaled precipitates on shape memory behavior of Ti-50.9 at\% Ni alloy. Acta Mater. 2005, 53, 4545-4554. [CrossRef]

25. Razov, A.; Motorin, A.; Nakhatova, G. Nonmonotonic two-way shape memory in titanium nickelide. J. Alloy. Compd. 2013, 577, S164-S167. [CrossRef]

26. Zel'dovich, V.I.; Sobyanina, G.A.; Rinkevich, O.S. Influence of prestrain on the shape-memory effect and martensite structure in titanium nickelide: I. Dilatometric effects of martensitic transformations. Phys. Metals Metallogr. 1996, 81, 305-312.

27. Grishkov, V.N.; Lotkov, A.I.; Baturin, A.A.; Timkin, V.N.; Zhapova, D.Y. Comparative analysis of inelastic strain recovery and plastic deformation in a Ti49.1Ni50.9 (at \%) alloy under torsion and bending. AIP Conf. Proc. 2015, 1683, 020067. [CrossRef]

28. Lotkov, A.I.; Grishkov, V.N.; Timkin, V.; Baturin, A.; Zhapova, D.Y. Yield stress in titanium nickelide-based alloys with thermoelastic martensitic transformations. Mater. Sci. Eng. A 2019, 744, 74-78. [CrossRef] 
29. Belyaev, S.P.; Volkov, A.E.; Resnina, N. Alternate stresses and temperature variation as factors of influence of ultrasonic vibration on mechanical and functional properties of shape memory alloys. Ultrasonics 2014, 54, 84-89. [CrossRef]

30. Lu, H.; Yang, C.; Li, X.; Cheng, Q.; Ma, H.; Wang, Z.; Qu, S. Microstructure evolution and superelasticity of Ti-24Nb-xZr alloys fabricated by spark plasma sintering. J. Alloy. Compd. 2020, 823, 153875. [CrossRef]

31. Liu, S.; Han, S.; Zhang, L.; Chen, L.-Y.; Wang, L.; Tang, Y.; Liu, J.; Tang, H.; Zhang, L.-C. Strengthening mechanism and micropillar analysis of high-strength $\mathrm{NiTi-Nb}$ eutectic-type alloy prepared by laser powder bed fusion. Compos. Part B Eng. 2020, 200, 108358. [CrossRef]

32. Jiang, D.; Kyriakides, S.; Bechle, N.J.; Landis, C.M. Bending of pseudoelastic NiTi tubes. Int. J. Solids Struct. 2017, 124, 192-214. [CrossRef]

33. Gall, K.; Sehitoglu, H.; Chumlyakov, Y.; Kireeva, I. Tension-compression asymmetry of the stress-strain response in aged single crystal and polycrystalline NiTi. Acta Mater. 1999, 47, 1203-1217. [CrossRef]

34. Ryklina, E.; Prokoshkin, S.; Vachiyan, K. Nanostructured Titanium Nickelide: Realization of abnormally high recovery strain. IOP Conf. Ser. Mater. Sci. Eng. 2014, 63, 012110. [CrossRef]

35. Polyakova-Vachiyan, K.A.; Prokoshkin, S.D.; Dubinskii, S.M.; Ryklina, E.P. Dependence of the functional characteristics of thermomechanically processed titanium nickelide on the size of the structural elements of austenite. Phys. Metals Metall. 2016, 117, 817-827. [CrossRef]

36. Polyakova, K.; Ryklina, E.; Prokoshkin, S. Thermomechanical response of Titanium Nickelide on austenite grain/subgrain size. Mater. Today Proc. 2017, 4, 4836-4840. [CrossRef]

37. ASTM F2004-05. Standard Test Method for Transformation Temperature of Nickel-Titanium Alloys by Thermal Analysis; ASTM International: West Conshohocken, PA, USA, 2010.

38. Kuranova, N.N.; Gunderov, D.V.; Uksusnikov, A.N.; Luk'Yanov, A.V.; Yurchenko, L.I.; Prokof'Ev, E.A.; Pushin, V.G.; Valiev, R.Z. Effect of heat treatment on the structural and phase transformations and mechanical properties of TiNi alloy subjected to severe plastic deformation by torsion. Phys. Metals Metall. 2009, 108, 556-568. [CrossRef]

39. Ryklina, E.P.; Prokoshkin, S.D.; Chernavina, A.A. Peculiarities of implementation of abnormally high shape memory effects in thermomechanically treated Ti-Ni alloys. Inorg. Mater. Appl. Res. 2013, 4, 348-355. [CrossRef]

40. Kolobova, A.Y.; Ryklina, E.P.; Prokoshkin, S.D.; Inaekyan, K.E.; Brailovskii, V. Study of the Evolution of the Structure and Kinetics of Martensitic Transformations in a Titanium Nickelide upon Isothermal Annealing after Hot Helical Rolling. Phys. Metals Metall. 2018, 119, 134-145. [CrossRef]

41. Gunderov, D.; Maksutova, G.; Churakova, A.; Lukyanov, A.; Kreitcberg, A.; Raab, G.; Sabirov, I.; Prokoshkin, S. Strain rate sensitivity and deformation activation volume of coarse-grained and ultrafine-grained TiNi alloys. Scr. Mater. 2015, 102, 99-102. [CrossRef]

42. Otsuka, K.; Ren, X. Physical metallurgy of Ti-Ni-based shape memory alloys. Prog. Mater. Sci. 2005, 50, 511-678. [CrossRef]

43. Khmelevskaya, I.; Komarov, V.; Kawalla, R.; Prokoshkin, S.; Korpala, G. Effect of Biaxial Isothermal Quasi-Continuous Deformation on Structure and Shape Memory Properties of Ti-Ni Alloys. J. Mater. Eng. Perform. 2017, 26, 4011-4019. [CrossRef] 